\title{
DIVERSIDADE GENOTÍPICA E PATOGÊNICA DE Colletotrichum musae NO ESTADO DE PERNAMBUCO ${ }^{1}$
}

\author{
PAULO CÉZAR DAS MERCÊS SANTOS², WALÉRIA GUERREIRO LIMA³, \\ CÍNTIA DE SOUSA BEZERRA4 ${ }^{4}$, SAMI JORGE MICHEREFF', \\ MARCOS PAZ SARAIVA CÂMARA ${ }^{6}$
}

RESUMO - Sessenta isolados de Colletotrichum oriundos de campos de produção de banana dos Municípios de Vicência, São Vicente Férrer e Machados, no Estado de Pernambuco, foram avaliados quanto a características morfológicas, moleculares, culturais, de virulência e de diversidade genética. Os isolados foram identificados como C. musae, tendo a maioria conídios retos, oblongos, com ápices arredondados. A taxa de crescimento micelial variou de 1,36 a 1,91 cm/dia. Foram encontrados três grupos de coloração para as colônias: branca, creme e salmão, enquanto a presença de setores variou de 0 a 8 por isolado e, na maioria dos isolados $(73,3 \%)$, houve a presença de microescleródios. A diferença em virulência foi significativa para a área abaixo da curva de progresso da doença, indicando variabilidade entre os isolados. O dendrograma gerado pela análise UPGMA dos marcadores ISSR-PCR revelou a formação de três grupos pelo coeficiente de similaridade de Dice, os quais correspondem, na sua maioria, às três áreas amostradas.

Termos para indexação: Musa sp., antracnose, doença pós-colheita, morfologia, ISSR-PCR.

\section{DIVERSITY GENOTYPIC AND PATHOGENIC OF Colletotrichum musae IN PERNAMBUCO}

\begin{abstract}
Sixty Colletotrichum isolates originating from fields producing banana in the municipalities of Vicência, São Vicente Férrer and Machados in the State of Pernambuco were evaluated for physiological, morphological, molecular, cultural, virulence and genetic diversity characteristics. The isolates were identified as $C$. musae, with most conidia, straight, oblong with rounded summits. The mycelial growth rate ranged from 1.36 to $1.91 \mathrm{~cm} /$ day. Three groups of staining for colonies were found: white, cream and salmon, while the presence of sectors ranged from 0 to 8 per isolate, and in most isolates (73.3\%) there were the presence of microsclerotia. The difference in virulence was significant for the area under the disease progress curve, indicating variability among isolates. The dendrogram generated by UPGMA analysis of ISSR-PCR markers revealed the formation of three groups by Dice similarity coefficient which correspond mostly to the three sampled areas.
\end{abstract}

Index terms: Musa sp., anthracnose, postharvest disease, morphology, ISSR-PCR.

${ }^{1}$ (Trabalho 034-14). Recebido em: 23-01-2014. Aceito para publicação em: 15-01-2015.

${ }^{2}$ Mestre em Fitopatologia. Aluno do Curso de Pós-graduação em Fitopatologia, Universidade Federal Rural de Pernambuco, Departamento de Agronomia, Área de Fitossanidade, Rua Dom Manoel de Medeiros, s/n, Dois Irmãos 52171-900. Recife-PE. E-mail: pcmerces@ bol.com.br

${ }^{3}$ Dra. em Fitopatologia. Bolsista PNPD/Capes, Universidade Federal Rural de Pernambuco, Departamento de Agronomia, Área de Fitossanidade, Rua Dom Manoel de Medeiros, s/n, Dois Irmãos 52171-900. Recife-PE. E-mail: wagueli@hotmail.com

${ }^{4}$ Dra. em Fitopatologia Universidade Federal Rural de Pernambuco, Departamento de Agronomia, Área de Fitossanidade, Rua Dom Manoel de Medeiros, s/n. Dois Irmãos 52171-900. Recife-PE. E-mails: wagueli@hotmail.com; cintiasbezerra@gmail.com ${ }^{5}$ Dr. em Fitopatologia. Professor, Universidade Federal Rural de Pernambuco, Departamento de Agronomia, Área de Fitossanidade, Rua Dom Manoel de Medeiros, s/n, Dois Irmãos 52171-900. Recife-PE. E-mail: sami@depa.ufrpe.br

${ }^{6} \mathrm{Ph}$. D. em Fitopatologia. Professor, Universidade Federal Rural de Pernambuco, Departamento de Agronomia, Área de Fitossanidade, Rua Dom Manoel de Medeiros, s/n, Dois Irmãos 52171-900. Recife-PE. E-mail: mcamara@depa.ufrpe.br 


\section{INTRODUÇÃO}

Dentre as patologias pós-colheita da banana (Musa L. spp.), a antracnose causada pelo fungo Colletotrichum musae (Berk. \& M.A. Curtis) Arx representa o mais grave problema em todas as regiões produtoras do mundo (CORDEIRO et al., 2005; VENTURA; HINZ, 2002). A doença geralmente ocorre na fase de maturação; entretanto, o fungo infecta os frutos verdes no campo de produção, e as infecções permanecem quiescentes até o início do estádio de maturação (CORDEIRO; MATOS, 2005; CORDEIRO et al., 2005).

Por muitos anos, a caracterização morfológica de C. musae gerou dados ambíguos que podem levar à classificação dessa espécie como sendo $C$. gloeosporioides (Penz.) Penz. \& Sacc. No entanto, trabalhos recentes desenvolvidos com isolados de banana determinaram as características fenotípicas e moleculares classificando essa espécie como um grupo monofilético dentro do complexo " $C$. gloeosporioides" (PHOTITA et al., 2005; ZAKARIA et al., 2009; ABD-ELSALAM et al., 2010). Como o isolado da espécie-tipo descrita para C. musae foi perdido durante o processo de conservação no pericarpo de banana, um neótipo foi designado por Su et al. (2011). Essa espécie apresenta alto grau de especificidade em relação ao gênero Musa (UDAYANGA et al., 2013).

Estudos de diversidade genética também são bastante úteis para estabelecer a estrutura de uma determinada população e o seu potencial evolutivo numa dada área de ocorrência da doença e a técnica de Inter-Simple Sequence Repeat-Polymerase Chain Reaction (ISSR-PCR), por ser um marcador dominante, pode ser uma alternativa viável para tais estudos. Em C. musae, nenhum estudo do tipo conseguiu fazer uma associação entre a variabilidade genotípica e a origem dos isolados em diferentes áreas de cultivos de banana. Medeiros et al. (2010) usaram essa técnica para estudar a variabilidade de isolados de Colletotrichum provenientes de vários hospedeiros, conseguindo demonstrar a diferença entre os isolados, assim como diferenciar as espécies C. gloeosporioides, C. acutatum J.H. Simmonds e $C$. sublineola Henn. ex Sacc. \& Trotter em seis grupos, anteriormente separados por primers específicos.

O entendimento das dinâmicas populacionais do patógeno é importante para predizer as respostas dessas populações às diferentes medidas de controle adotadas (FREEMAN et al., 1997). McDonald e Linde (2002) citam, por exemplo, patógenos com maior potencial evolutivo impõem maior risco de sobrepor os efeitos dos genes de resistência ou o desenvolvimento para anular o efeito dos métodos de controle, como a aplicação de fungicidas, que, por sua vez, é o método atualmente adotado para controlar a antracnose da banana.

Dessa forma, este trabalho teve como objetivos estudar as características morfológicas, culturais, moleculares e patogênicas de isolados de C. musae oriundos de diferentes áreas produtoras de bananas no Estado de Pernambuco e analisar a diversidade genética por meio de ISSR-PCR.

\section{MATERIAL E MÉTODOS}

Sessenta isolados de C. musae foram obtidos de bananas cvs. Pacovan e Prata, coletadas nos principais municípios produtores de Pernambuco: Vicência $07^{\circ} 39^{\prime} 38.87^{\prime}$ 'S $35^{\circ} 19^{\prime} 44.91^{\prime \prime} \mathrm{O}$ e $07^{\circ}$ 40’ 49.32" S 3524' 41.06" O (Zona da Mata Norte Pernambucana), São Vicente Férrer 07 39' 38.87', S 35 19' 44.91" O e Machados $07^{\circ} 41^{\prime}$ '09' S $35^{\circ}$ 30' 54" O (Agreste Pernambucano) (Figura 1). Foram coletados dois frutos por planta, sendo as plantas escolhidas aleatoriamente dentro das áreas de plantio, totalizando 20 plantas por área amostrada. $\mathrm{O}$ isolamento foi efetuado quando os frutos se encontravam no estádio de maturação comercial I, em meio BDA suplementado com $50 \mu \mathrm{g} / \mathrm{mL}$ de cloridrato de tetraciclina. Culturas monospóricas foram obtidas conforme a metodologia descrita por Ho e Ko (1997) e incorporadas à Coleção de Fungos Fitopatogênicos "Professora Maria Menezes" - CMM, da Universidade Federal Rural de Pernambuco, localizada no Recife, Pernambuco, Brasil.

Os isolados monospóricos foram cultivados em placas contendo meio BDA mantidas em fotoperíodo de $12 \mathrm{~h}$, à temperatura de $25 \pm 1{ }^{\circ} \mathrm{C}$. Para análise do crescimento micelial, foi realizada diariamente a mensuração do diâmetro médio das colônias em dois sentidos perpendiculares para o cálculo da taxa de crescimento micelial (TCMD) de cada isolado. $\mathrm{O}$ delineamento experimental utilizado foi o inteiramente casualizado, com 4 repetições por isolado, sendo cada repetição constituída por uma placa. Adicionalmente, ao final do experimento, foi realizada a caracterização cultural observando a coloração das colônias e a cor do reverso, além do relevo (comportamento do crescimento micelial) e da formação de setores (análise visual e contagem do número de setores).

$\mathrm{Na}$ análise morfológica, adotaram-se os procedimentos utilizados por Than et al. (2008) com modificações, caracterizando o tamanho e o formato dos conídios. Esporos de colônias de Colletotrichum 
foram utilizados em preparações microscópicas, montadas e observadas ao microscópio óptico, usando a objetiva de $40 \times$. Posteriormente, o comprimento (C) e a largura (L) de 400 conídios, por isolado, foram medidos utilizando o software Motic Images Plus 2.0 (Motic China Group Co., Ltd, Xiamen, Fujian, China). Com os dois dados, foi calculada a relação comprimento/largura $(\mathrm{C} / \mathrm{L})$. A partir das imagens fotografadas, procedeu-se à avaliação dos formatos de 100 conídios por isolado de acordo com a descrição de Sutton (1992) e a escala proposta por Tozze Júnior (2007), em que o formato 1 é reto, fusiforme, com ápices afilados; o formato 2 é reto, oblongo, com ápices arredondados; o formato 3 é reto, clavado, afilado em uma extremidade e redondo na outra, e o formato 4 é reto, com constrição. Os resultados foram transformados em porcentagem para cada formato de conídios apresentado por isolado.

$\mathrm{Na}$ caracterização da virulência, foram utilizados frutos sadios da cultivar Pacovan no estádio de maturação II. Os frutos previamente desinfestados foram depositados em bandejas plásticas e inoculados sem e com ferimentos com auxílio de uma microagulha em dois pontos equidistantes. Em seguida, foram depositadas 30 $\mu \mathrm{L}$ de suspensão $\left(10^{6}\right.$ esporos $\left./ \mathrm{mL}\right)$ de conídios de cada isolado sobre o local dos pontos com e sem ferimentos. O controle foi feito por meio do depósito de $30 \mu \mathrm{L}$ de água destilada esterilizada sobre a superfície do fruto. Após a inoculação, os frutos foram mantidos em sala de incubação, à temperatura de $27 \pm 2{ }^{\circ} \mathrm{C}$, em fotoperíodo de 12 horas, sendo previamente mantidos em câmara úmida por 24 horas.

As avaliações de severidade, foram realizadas diariamente, desde o aparecimento do sintoma até que lesões individuais não fossem mais distinguíveis. As medições foram feitas com uma régua flexível milimetrada, em dois sentidos diametralmente opostos. Com os dados diários de severidade foi calculada a área abaixo da curva de progresso da doença (AACPD), utilizando a regra do ponto médio ou método de integração trapezoidal (CAMPBELL; MADDEN, 1990). O delineamento foi inteiramente casualizado, com quatro repetições para cada tratamento, e a parcela experimental foi representada por uma fruta inoculada em dois pontos.

Para análise de diversidade genotípica e caracterização molecular, foi feita a extração do DNA genômico de 60 isolados monospóricos com sete dias de cultivo, em meio BDA, de acordo com o protocolo de Schäfer e Wöstemeyer (1992) modificado por Junghans et al. (1998). O DNA extraído foi ressuspendido, quantificado e armazenado a $-20{ }^{\circ} \mathrm{C}$. Os isolados foram caracterizados pela técnica de ISSR-PCR, utilizando três primers, GTG5 (5'GTG GTG GTG GTG GTG-3'), GACA (5'-GAC AGA CAG ACA GAC A-3') e 820 (5'-GTG TGT GTG TGT GTG TC-3') (Invitrogen ${ }^{\mathrm{TM}}$ ). A reação contendo $100 \mathrm{ng}$ de DNA foi realizada com $25 \mu \mathrm{L}$ do tampão $10 \times$ para PCR, $0,5 \mathrm{mM}$ de $\mathrm{MgCl}_{2}, 0,2$ $\mathrm{mM}$ de cada um dos quatro $\mathrm{dNTP}, 0,5 \mu \mathrm{M}$ de cada um dos oligonucleotídeos e 0,04 U de Platinum ${ }^{\circledR}$ Taq DNA Polymerase High Fidelity (Invitrogen ${ }^{\mathrm{TM}}$ ). A PCR foi realizada em termociclador com o programa: desnaturação inicial $95^{\circ} \mathrm{C}$ por $5 \mathrm{~min}, 30$ ciclos de 94 ${ }^{\circ} \mathrm{C}$ por $30 \mathrm{~s}, 45^{\circ} \mathrm{C}(820)$ ou $52{ }^{\circ} \mathrm{C}$ (GTG5 e GACA) por $45 \mathrm{~s}, 72{ }^{\circ} \mathrm{C}$ por 2 min e uma extensão final de 72 ${ }^{\circ} \mathrm{C}$ por $7 \mathrm{~min}$. Os produtos da PCR foram analisados em gel de agarose a 1,5\%, em tampão $1 \times$ Tris-acetato EDTA (40 mM Tris-acetato, 1 mM EDTA) por meio de eletroforese a $100 \mathrm{~V}$ por $2 \mathrm{~h}$ e visualizados em fotodocumentador após coloração com SyBR ${ }^{\circledR}$ Gold Nucleic Acid Gel Stain. Os tamanhos dos fragmentos amplificados foram estimados por comparação com o marcador molecular $1 \mathrm{~Kb}$ Plus DNA ${ }^{\circledR}$ Ladder $\left(\right.$ Invitrogen $^{\mathrm{TM}}$ ).

As análises dos dados morfológicos e de virulência foram conduzidas em duas etapas: inicialmente, para cada variável, verificou-se a adequabilidade dos resíduos às pressuposições da distribuição normal. Confirmando essa adequabilidade, procedeu-se à análise de variância univariada que foi utilizada para identificar grupos de isolados dentro de cada variável. Os valores de crescimento micelial foram ajustados ao modelo de regressão linear simples $(y=a+b . x)$, tendo o tempo (em dias) como variável independente, e o crescimento micelial (em $\mathrm{cm})$ como dependente. A taxa de crescimento micelial diária para cada isolado (cm/dia) foi estimada pelo parâmetro " $b$ " da equação de regressão, considerando os dados de apenas cinco dias de leitura. Em relação aos dados de morfometria de conídios, para cada isolado, foram calculados o valor médio e o intervalo de confiança $(P=0,05)$. A TCMD, comprimento, largura e relação $\mathrm{C} / \mathrm{L}$ dos conídios, AACPD de frutas inoculadas com e sem ferimentos foram submetidas à análise de variância, e as médias, comparadas pelo teste de agrupamento de Scott-Knott $(P=0,05)$, utilizando-se do programa estatístico Sisvar versão 5.0 (Universidade Federal de Lavras, Lavras-MG, Brasil).

Para a determinação da estrutura genética, foram analisados os 60 isolados das três áreas de plantio comercial. Os dados obtidos nos géis de eletroforese foram transformados em dados binários: 1 - para presença de bandas; e 0 - para 
ausência de bandas. A análise de diversidade genética da população foi realizada usando o programa POPGENE ${ }^{\circledR}$ version 1.32 (Population Genetic Analysis, University of Alberta, Edmonton, AB, CA) para executar a análise combinada dos dados obtidos e gerar os valores de diversidade gênica $(H)$, diversidade genética total $\left(H_{T}\right)$, diversidade genética intrapopulacional $\left(H_{S}\right)$, diferenciação genética interpopulacional $\left(G_{S T}\right)(\mathrm{NEI}, 1973,1978)$ e número de migrantes $\left(N_{m}\right)$.

A análise de diversidade genotípica para cada população e para a população total difere em riqueza, igualdade e diversidade, como descrito previamente, e foi calculado com os índices de Hill (1973): $N_{1}$ e $N_{2}$, em que $N_{1}=\mathrm{e}^{H}$, em que, $H$ refere-se ao índice de Shannon (1948): $H=-\Sigma p_{i} \times \ln \left(p_{i}\right)$, em que $p_{i}$ é a frequência observada do $i^{\text {th }}$ genótipo. $N_{1}$ representa o número de genótipos comuns de forma uniforme que podem produzir a mesma diversidade $H . N_{2}$ corresponde ao índice de diversidade genotípica presente em Stoddart e Taylor (1988): $G=1 / \Sigma p_{i}^{2}$. $N_{1}$ e $G$ medem quão eficazmente as concentrações populacionais proporcionais são distribuídas entre os diferentes genótipos. $G$ dá um peso maior ao número de genótipos abundantes, enquanto $N_{1}$ dá um peso maior a genótipos raros. $N_{1}$ geralmente fica entre o número de genótipos observados $\left(g_{\text {obs }}\right)$ e o valor de $G$. Foi realizado um bootstrapping usando 1.000 reamostragens com intervalo de confiança de 95\% (DIXON, 1993; GRÜNWALD et al., 2003). A riqueza genotípica que expressa o número de patótipos esperados na amostra foi estimada usando curvas de rarefação com base no tamanho da amostra da menor população (GRÜNWALD et al., 2003; HURLBERT, 1971). O índice de equitabilidade, que mede como os genótipos estão distribuídos na amostra $\left(E_{5}\right)$, foi calculado com a fórmula $\mathrm{E}_{5}$ $=(\mathrm{G}-1) /(N 1-1)($ ALATALO, 1981; LUDWIG; REYNOLDS, 1988; GRÜNWALD et al., 2003).

. Todas as análises foram executadas usando o software estatístico R version 2.15.0 (R Development Core Team, 2012, R Foundation for Statistical Computing, Vienna, VIE, AT).

A análise foi realizada em duas etapas: i) todos os 60 isolados representando a população total foram avaliados segundo os critérios descritos acima; e ii) as três populações foram analisadas separadamente, comparadas para diversidade genética e genotípica. Foi realizada uma avaliação da relação genética entre os isolados, através de uma análise de grupamento e, com base no coeficiente de similaridade de Dice (1945), foi construído um dendrograma pelo método Unweighted Pair Group Method with Arithmetic Mean (UPGMA), usando o software NTSYSpc ${ }^{\circledR}$ version 2.1 for Windows (Applied Biostatistics Inc., Port Jefferson, NY, USA) (Figura 2).

\section{RESULTADOS E DISCUSSÃO}

Os parâmetros das variáveis fisiológicas avaliadas neste trabalho estão de acordo com as observações já descritas por diversos autores para a espécie C. musae (PHOTITA et al., 2005; ZAKARIA et al., 2009; ABD-ELSALAM et al., 2010; SU et al., 2011). As médias obtidas com a taxa de crescimento micelial, além das características culturais que foram analisadas e agrupadas, estão apresentadas na Tabela 1. Os isolados de C. musae diferiram quanto à TCMD, com a formação de três grupos, pelo teste de ScottKnott $(P=0,05)$, e todos os isolados apresentaram crescimento médio superior a 1,0 cm/dia.

Na caracterização cultural, para os 60 isolados de C. musae, houve variação no que diz respeito à coloração das colônias. Foi possível fazer a separação em três grupos de coloração, que variou de branca, creme a salmão. Da mesma forma, comportou-se o reverso da placa (dados não mostrados). Quanto à topografia das colônias, houve predominância de micélio aéreo.

A maioria das colônias de C. musae desenvolveu micélio em setores regulares, que acompanharam o crescimento radial normal da colônia. A formação dos setores miceliais apareceu em isolados, independentemente da área de coleta. Para sete isolados (11,6\%), foi observado um único setor por colônia (placa), enquanto alguns isolados apresentaram mais de um por placa, com número máximo de oito setores formados. Roca-Magallanes et al. (2004) trabalhando com o complexo GlomerellaColletotrichum associado às sementes de algodão verificaram que as culturas sempre mantinham as mesmas características fenotípicas para a formação de setores, quando da realização de sucessivas transferências em meios de cultura. No presente trabalho, foi verificado esse efeito de formação de setores nas repicagens periódicas.

A presença de microescleródios, que funcionam como estruturas de resistência, foi observada em 44 isolados $(73,3 \%)$ e não houve a formação de setas, em meio de cultura, para nenhum dos isolados estudados. A detecção de microescleródios, em meios de cultura, é um passo importante para o manejo de doenças causadas por espécies de Colletotrichum, uma vez que a observação in vitro, dessa estrutura de sobrevivência dá uma ideia da diversidade do comportamento das espécies. O agente causal da antracnose do sorgo [C. graminicola (Ces.) G.W. 
Wilson.] sobrevive, de modo saprofítico, em colmos secos, por até 18 meses, principalmente na forma de microescleródios. O manejo dessa dessa doença pode ser realizada pela eliminação de restos culturais, visando a redução do inóculo primário (CASELA; FREDERIKSEN, 1993; FREDERIKSEN, 2000; COSTA et al., 2003).

Os dados referentes à caracterização morfológica dos conídios de C. musae estão apresentados na Tabela 1. Os conídios apresentaramse hialinos, retos, obtusos nas extremidades e alguns truncados na base, com presença de três formas predominantes: cilíndricas, elipsoides e clavadas. Tomando por base a classificação proposta por Tozze Júnior (2007), o formato de conídios que mais se destacou foi o 2 (reto, oblongo e ápices arredondados), com $63,2 \%$ do total de conídios, seguido pelo formato 3 (reto, clavado, afilado em uma extremidade e redondo na outra) com $26,0 \%$ de frequência. Os formatos 4 (reto, com constrição) e 1 (reto, fusiforme, com ápices afilados) apresentaram 9,4 e $1,4 \%$, respectivamente.

Em relação à aplicação do intervalo de confiança $(P=0,05)$ (dados não mostrados), para o comprimento, os valores médios variaram de 12,2 a 17,8 , para largura a variação foi de 3,8 a 6,1 , enquanto a relação $\mathrm{C} / \mathrm{L}$ foi de 2,4 a 4,5 . Houve diferença significativa entre as variáveis comprimento, largura e relação comprimento/largura, de acordo com o teste de Scott-Knott $(P=0,05)$, permitindo subdividir os isolados em nove, treze e doze grupos, respectivamente. Os limites inferior e superior do comprimento dos conídios foram 9,3 e 30,2 $\mu \mathrm{m}$, enquanto para a largura, os valores foram 2,6 e 12,6 $\mu \mathrm{m}$, e para a relação C/L, 1,1 e 7,5, com média geral $(n=6.000)$ de 15,0 × 4,9 $\mu \mathrm{m}$ e 3,1, para comprimento, largura e relação $\mathrm{C} / \mathrm{L}$, respectivamente.

Para todas as características fenotípicas avaliadas, foram observados padrões de variação dentro dos limites estabelecidos para C. musae (SUTTON, 1992). O comportamento variável de determinadas características fisiológicas e culturais de uma mesma espécie de Colletotrichum pode ser explicada pela condição heterozigótica para um determinado caráter das populações de biótipos que constituem essa espécie (COUTO; MENEZES, 2004). Esse comportamento é governado por diversos fatores que acabam influenciando sobre as características fenotípicas da espécie, de acordo com as condições ambientais e temporais de cultivo em que esta foi colocada.

Todos os isolados foram patogênicos em bananas, quando inoculados com ferimentos, e
20 isolados $(33,3 \%)$ não estabeleceram infecção quando inoculados sem ferimentos (Tabela 1). Essa observação é importante no que diz respeito aos cuidados no manuseio pós-colheita, visando a evitar danos mecânicos que possam facilitar a penetração e o estabelecimento das relações parasitárias de C. musae. Não houve correlação entre a origem dos isolados e a diferença na virulência quando inoculados em frutos de bananeira.

As bananas inoculadas, neste trabalho, apresentaram sintomas típicos da antracnose. Esses sintomas foram lesões necróticas de coloração marrom-escura que se tornaram deprimidas conforme a colonização do tecido, algumas de formato circulares e outras que eram delimitadas pelas quinas da casca. Posteriormente, as lesões eram tomadas pelo sinal do fitopatógeno, com a formação de pequenas pontuações (acérvulos) com a presença de massas de esporos de coloração alaranjada. Os frutos utilizados como tratamento-controle não apresentaram sintomas no decorrer da condução do experimento.

A AACPD variou de 2,11 (CMM 3142) a 5,12 (CMM 3197) nas inoculações com ferimentos e 0,44 (CMM 3129) a 3,10 (CMM 3125) para as inoculações sem ferimentos, indicando a existência de variação na virulência entre os isolados. De acordo com o teste de Scott-Knott $(P=0,05)$, houve diferenças significativas entre os isolados, permitindo subdividi-los em 2 grupos para as inoculações realizadas com e sem ferimentos, respectivamente.

Isolados de $C$. musae podem apresentar comportamento diferenciado entre si, quando inoculados na própria cultivar de origem de obtenção desses isolados, ou até mesmo nem causar doença, no caso de um isolado obtido em uma cultivar e, posteriormente, inoculado em outra (COUTO et al., 2002). Fato semelhante foi observado neste trabalho. Os ferimentos realizados na casca da banana podem ter facilitado a entrada do fitopatógeno, promovendo o processo de infecção e colonização, já que muitas doenças são iniciadas através de ferimentos. Para frutos do tratamento sem ferimentos, nos quais os isolados não conseguiram causar infecções, a ausência de sintomas, entretanto, não significa que o fitopatógeno não iniciou o processo infeccioso.

Foram identificados 20 haplótipos ISSR entre os 60 isolados estudados. Um alto grau de similaridade genética foi encontrado entre os isolados, com 11 grupos de isolados com similaridade genética máxima entre eles, o maior destes grupos com 20 isolados, todos da população de Machados. Ao analisar o dendograma (Figura 2), encontram-se dois isolados do município de Vicência (CMM3120 
e CMM3122) agrupados com os isolados de Machados, e dois isolados de São Vicente Férrer (CMM3179 e CMM3180) agrupados com os de Vicência. Apesar disso, quando os isolados são agrupados em populações, o dendograma revela maior similaridade genética entre as populações de Machados e São Vicente Férrer (Figura 2; Tabela 3). Nenhum dos haplótipos encontrados é compartilhado entre as três populações.

Os primers GACA, GTG5 e 820 também foram úteis para avaliar a diversidade genética entre isolados de C. gloeosporioides (FREEMAN; SHABI, 1996) provenientes de abacate e amêndoa de Israel e Estados Unidos e, tal como apresentado neste estudo, verificaram que estes foram agrupados de acordo com sua origem geográfica.

A heterozigosidade esperada $\left(H_{S}\right)$, indicando o nível de diversidade genética intrapopulacional, foi de 0,109 , representando $35 \%$ da diversidade genética total $\left(H_{T}=0,312\right)$. Assim, na população total, a maior parte da diversidade genética encontrada é devido ao alto nível de diferenciação entre populações $\left(G_{S T}\right.$ $=0,649)$. Apesar do alto valor de $G_{S T}$, o número de indivíduos que migram por geração, número de migrantes $(\mathrm{Nm}=0,270)$ encontrado é suficiente para contrapor os efeitos da deriva e, assim, impede grande divergência genética entre as populações (Tabela 2). Quando as populações foram analisadas aos pares, os valores de $G_{S T}$ foram menores que o da população total, variando de 0,334 a 0,573 , mas ainda revelando uma moderada distância genética entre as populações. As populações mais divergentes foram São Vicente Férrer e Vicência, e esses dados foram confirmados pelos valores de identidade genética que variaram de 0,56 a 0,71, com a maior identidade entre as populações de Machados e São Vicente Férrer (Tabela 2).

A partir dos valores de $\mathrm{G}_{\mathrm{ST}}$ de cada par de populações, foi inferida a estimativa de fluxo gênico entre elas, entre São Vicente e Vicência, $N m=0,37$ e Machados e Vicência, $N m=0,86$, insuficiente para contrapor os efeitos da deriva e, consequentemente, permitindo divergência entre populações. Por outro lado, entre Machados e São Vicente Férrer, o fluxo gênico foi $N m=1$, valor suficiente para manter as populações geneticamente semelhantes (Tabela 3).

A diversidade genotípica das populações variou de 1 a 7,68. A riqueza genotípica estimada pela rarefação com menor tamanho de amostra $(n=20)$ foi baixa na população de Machados e alta para São Vicente Férrer. A equitabilidade genotípica foi alta em todas as populações, com valores entre 0,85 e 1, a população de Machados apresentou a equitabilidade máxima 1 , quando cada genótipo ocorre na mesma frequência, no caso desta população, um único genótipo distribuído igualmente na população. A diversidade genotípica da população de Machados foi significativamente diferente das populações de Vicência e São Vicente Ferrer, visto que não houve sobreposição dos intervalos de confiança calculados com base no erro-padrão de cada estimativa. Entre as populações de Vicência e São Vicente Ferrer, houve sobreposição dos intervalos de confiança, revelando que não há diferenças significativas na diversidade genotípica destas populações. A diversidade genotípica da população total foi $13 \%$ do máximo possível quando $G=n$, ou seja, todos os isolados têm um fingerprint de DNA diferente. A diversidade gênica foi moderada nas populações de Vicência e São Vicente Férrer, 0,2 e 0,12 respectivamente. Para Machados, não houve diversidade gênica $(H=0,0)$ (Tabela 3).

A análise dos índices de diversidade genotípica confirmou a variabilidade dos isolados de C. musae dentro de cada área, exceto na população de Machados. No entanto, quando a população foi vista como um todo, a variabilidade foi moderada quando comparada com o número total de genótipos e o número de isolados estudados. A ocorrência de um grande número de isolados geneticamente idênticos e concentrados geograficamente pode ser explicada pelo modo de dispersão do Colletotrichum, que ocorre com respingos de água e que não alcança grandes distâncias, além disso, os locais em estudo, estão isolados por barreiras naturais.

Os índices também indicaram a ocorrência de fluxo gênico, provavelmente, devido ao fungo ser transportado via material de propagação e não haver fiscalização sanitária entre regiões. Ademais, a reprodução assexuada pode ser responsável pela manutenção do padrão populacional de $C$. musae.

Este é o primeiro estudo relatando a diversidade genética em populações de $C$. musae associadas à antracnose da banana via ISSR-PCR. Essa técnica pode ser uma alternativa viável para estudos de variabilidade de C. musae, visto que fungos desse gênero, quando analisados em relação à morfologia, testes bioquímicos e fisiologia, são bastante variáveis e mostram-se bastante influenciados pelas condições ambientais. 
TABELA 1 - Características fisiológicas, culturais, morfológicas e de virulência de isolados de Colletotrichum musae obtidos de banana com sintomas de antracnose e provenientes de três municípios do Estado de Pernambuco.

\begin{tabular}{|c|c|c|c|c|c|c|c|c|c|c|}
\hline \multirow{2}{*}{ Isolado } & \multirow{2}{*}{$\mathrm{LC}^{1}$} & \multirow{2}{*}{$\operatorname{TCMD}(\mathrm{cm} / \mathrm{dia})^{2}$} & \multirow{2}{*}{${ }^{2} \mathrm{ME}^{3}$} & \multirow{2}{*}{ Setor $^{4}$} & \multirow{2}{*}{$\begin{array}{l}\text { Cor da } \\
\text { colônia }^{5}\end{array}$} & \multirow{2}{*}{$\begin{array}{c}\text { Comprimento } \\
(\mu \mathrm{m})^{6}\end{array}$} & \multirow{2}{*}{$\begin{array}{l}\text { Largura } \\
(\mu \mathrm{m})^{7}\end{array}$} & \multirow{2}{*}{$\begin{array}{c}\text { Relação } \\
\mathrm{C} / \mathrm{L}^{8}\end{array}$} & \multicolumn{2}{|c|}{$\mathrm{AACPD}^{9}$} \\
\hline & & & & & & & & & $\mathrm{CF}^{10}$ & $\mathrm{SF}^{11}$ \\
\hline CMM 3120 & VIC & $1,65 b^{*}$ & $\mathrm{P}$ & 1 & Branca & $15,26 \mathrm{~d}$ & $3,78 \mathrm{n}$ & $4,07 \mathrm{c}$ & $2,97 \mathrm{~b}$ & 0 \\
\hline CMM 3122 & VIC & $1,88 \mathrm{a}$ & A & 0 & Creme & $16,05 \mathrm{c}$ & $5,21 \mathrm{e}$ & $3,11 \mathrm{~h}$ & $3,25 \mathrm{~b}$ & 0 \\
\hline CMM 3125 & VIC & $1,59 \mathrm{~b}$ & $\mathrm{P}$ & 0 & Creme & $13,75 \mathrm{~g}$ & $4,77 \mathrm{~h}$ & $2,91 \mathrm{i}$ & $4,28 \mathrm{a}$ & $3,10 \mathrm{a}$ \\
\hline CMM 3126 & VIC & $1,64 \mathrm{~b}$ & A & 0 & Branca & $12,89 \mathrm{~h}$ & $4,55 \mathrm{j}$ & $2,86 \mathrm{i}$ & $2,71 \mathrm{~b}$ & 0 \\
\hline CMM 3127 & VIC & $1,51 \mathrm{c}$ & A & 0 & Creme & $16,18 \mathrm{c}$ & $5,12 \mathrm{f}$ & $3,20 \mathrm{~g}$ & $4,02 \mathrm{a}$ & $1,27 \mathrm{~b}$ \\
\hline CMM 3129 & VIC & $1,65 \mathrm{~b}$ & A & 0 & Salmão & $16,35 \mathrm{~b}$ & $5,84 \mathrm{~b}$ & $2,85 \mathrm{i}$ & $2,87 \mathrm{~b}$ & $0,44 \mathrm{~b}$ \\
\hline CMM 3132 & VIC & $1,72 \mathrm{a}$ & $\mathrm{P}$ & 0 & Salmão & $15,24 \mathrm{~d}$ & $5,36 \mathrm{e}$ & $2,86 \mathrm{i}$ & $4,03 \mathrm{a}$ & 0 \\
\hline CMM 3133 & VIC & $1,82 \mathrm{a}$ & $\mathrm{P}$ & 3 & Salmão & $13,98 \mathrm{f}$ & $5,70 \mathrm{c}$ & $2,49 \mathrm{~d}$ & $4,32 \mathrm{a}$ & $0,67 \mathrm{~b}$ \\
\hline CMM 3135 & VIC & $1,73 \mathrm{a}$ & $\mathrm{P}$ & 5 & Branca & $14,88 \mathrm{e}$ & $5,78 \mathrm{~b}$ & 2,591 & $3,14 \mathrm{~b}$ & 0 \\
\hline CMM 3136 & VIC & $1,79 \mathrm{a}$ & A & 0 & Salmão & $13,60 \mathrm{~g}$ & $4,77 \mathrm{~h}$ & $2,87 \mathrm{i}$ & $4,36 \mathrm{a}$ & $2,08 \mathrm{a}$ \\
\hline CMM 3140 & VIC & $1,84 \mathrm{a}$ & $\mathrm{P}$ & 0 & Salmão & $16,59 \mathrm{~b}$ & $5,73 \mathrm{c}$ & $2,95 \mathrm{i}$ & $3,60 \mathrm{~b}$ & $0,73 \mathrm{~b}$ \\
\hline CMM 3142 & VIC & $1,52 \mathrm{c}$ & $\mathrm{P}$ & 8 & Salmão & $16,97 \mathrm{~b}$ & $6,03 \mathrm{a}$ & $2,85 \mathrm{i}$ & $2,11 \mathrm{~b}$ & $1,61 \mathrm{a}$ \\
\hline CMM 3144 & VIC & $1,45 \mathrm{c}$ & A & 2 & Branca & $15,05 \mathrm{~d}$ & $5,38 \mathrm{e}$ & $2,82 \mathrm{i}$ & $3,16 \mathrm{~b}$ & 0 \\
\hline CMM 3146 & VIC & $1,45 \mathrm{c}$ & A & 0 & Branca & $14,21 \mathrm{f}$ & $5,31 \mathrm{e}$ & $2,69 \mathrm{j}$ & $3,03 \mathrm{~b}$ & $0,85 \mathrm{~b}$ \\
\hline CMM 3148 & VIC & $1,68 \mathrm{a}$ & A & 1 & Salmão & $12,37 \mathrm{i}$ & $4,42 \mathrm{j}$ & $2,82 \mathrm{i}$ & $3,54 \mathrm{~b}$ & $1,20 \mathrm{~b}$ \\
\hline CMM 3152 & VIC & $1,69 \mathrm{a}$ & $\mathrm{P}$ & 0 & Salmão & $16,38 \mathrm{~b}$ & $5,27 \mathrm{e}$ & $3,16 \mathrm{~g}$ & $3,06 \mathrm{~b}$ & 0 \\
\hline CMM 3153 & VIC & $1,74 \mathrm{a}$ & $\mathrm{P}$ & 0 & Salmão & $17,64 \mathrm{a}$ & $3,95 \mathrm{~m}$ & $4,51 \mathrm{a}$ & $3,28 \mathrm{~b}$ & 0 \\
\hline CMM 3155 & VIC & $1,75 \mathrm{a}$ & $\mathrm{P}$ & 0 & Salmão & $13,96 \mathrm{f}$ & $4,64 \mathrm{i}$ & $3,02 \mathrm{~h}$ & $3,56 \mathrm{~b}$ & 0 \\
\hline CMM 3156 & VIC & $1,57 \mathrm{~b}$ & A & 0 & Branca & $14,74 \mathrm{e}$ & $4,98 \mathrm{f}$ & $2,99 \mathrm{~h}$ & 4,16 a & $2,51 \mathrm{a}$ \\
\hline CMM 3157 & VIC & $1,81 \mathrm{a}$ & $\mathrm{P}$ & 0 & Salmão & $15,72 \mathrm{c}$ & $5,85 \mathrm{~b}$ & $2,72 \mathrm{j}$ & $4,72 \mathrm{a}$ & $2,01 \mathrm{a}$ \\
\hline CMM 3158 & SVF & $1,80 \mathrm{a}$ & $\mathrm{P}$ & 0 & Salmão & $16,02 \mathrm{c}$ & $5,49 \mathrm{~d}$ & $2,95 \mathrm{i}$ & $3,65 \mathrm{~b}$ & $0,62 \mathrm{~b}$ \\
\hline CMM 3161 & SVF & $1,83 \mathrm{a}$ & $\mathrm{P}$ & 8 & Salmão & $15,43 \mathrm{~d}$ & 4,141 & $3,78 \mathrm{~d}$ & $3,42 \mathrm{~b}$ & $1,74 \mathrm{a}$ \\
\hline CMM 3162 & SVF & $1,60 \mathrm{~b}$ & $\mathrm{P}$ & 1 & Creme & $16,64 \mathrm{~b}$ & $4,68 \mathrm{i}$ & 3,59 e & $3,11 \mathrm{~b}$ & $0,80 \mathrm{~b}$ \\
\hline CMM 3163 & SVF & $1,82 \mathrm{a}$ & $\mathrm{P}$ & 0 & Creme & $13,13 \mathrm{~g}$ & $4,80 \mathrm{~h}$ & $2,75 \mathrm{j}$ & $3,54 \mathrm{~b}$ & 0 \\
\hline CMM 3165 & SVF & $1,80 \mathrm{a}$ & A & 0 & Creme & $13,22 \mathrm{c}$ & $4,65 \mathrm{i}$ & $2,86 \mathrm{i}$ & $3,54 \mathrm{~b}$ & $0,77 \mathrm{~b}$ \\
\hline CMM 3168 & SVF & $1,82 \mathrm{a}$ & $\mathrm{P}$ & 3 & Salmão & $17,80 \mathrm{a}$ & $5,52 \mathrm{~d}$ & $3,25 \mathrm{~g}$ & $4,02 \mathrm{a}$ & $0,78 \mathrm{~b}$ \\
\hline CMM 3175 & SVF & $1,67 \mathrm{a}$ & A & 0 & Salmão & $13,49 \mathrm{~g}$ & $4,73 \mathrm{~h}$ & $2,88 \mathrm{i}$ & $4,66 \mathrm{a}$ & $1,23 \mathrm{~b}$ \\
\hline CMM 3177 & SVF & $1,78 \mathrm{a}$ & $\mathrm{P}$ & 0 & Salmão & $13,98 \mathrm{f}$ & $4,99 \mathrm{f}$ & $2,82 \mathrm{i}$ & 3,94 a & $1,24 \mathrm{~b}$ \\
\hline CMM 3179 & SVF & $1,87 \mathrm{a}$ & $\mathrm{P}$ & 0 & Salmão & $15,66 \mathrm{c}$ & $4,96 \mathrm{f}$ & $3,20 \mathrm{~g}$ & $4,24 \mathrm{a}$ & $2,31 \mathrm{a}$ \\
\hline CMM 3180 & SVF & $1,47 \mathrm{c}$ & $\mathrm{P}$ & 5 & Creme & $16,14 \mathrm{c}$ & $4,67 \mathrm{i}$ & $3,50 \mathrm{e}$ & $3,29 \mathrm{~b}$ & $0,88 \mathrm{~b}$ \\
\hline CMM 3183 & SVF & $1,80 \mathrm{a}$ & A & 0 & Branca & $17,52 \mathrm{~b}$ & $4,63 \mathrm{i}$ & $3,83 \mathrm{~d}$ & $2,51 \mathrm{~b}$ & 0 \\
\hline CMM 3187 & SVF & $1,69 \mathrm{a}$ & $\mathrm{P}$ & 0 & Salmão & $16,20 \mathrm{c}$ & $4,69 \mathrm{i}$ & $3,49 \mathrm{e}$ & $3,30 \mathrm{~b}$ & $1,98 \mathrm{a}$ \\
\hline CMM 3188 & SVF & $1,74 \mathrm{a}$ & $\mathrm{P}$ & 0 & Salmão & $14,48 \mathrm{e}$ & $4,63 \mathrm{i}$ & $3,20 \mathrm{~g}$ & $3,44 \mathrm{~b}$ & $2,49 \mathrm{a}$ \\
\hline CMM 3189 & SVF & $1,67 \mathrm{a}$ & $\mathrm{P}$ & 0 & Branca & $13,98 \mathrm{f}$ & 4,161 & $3,40 \mathrm{f}$ & $2,81 \mathrm{~b}$ & 0 \\
\hline CMM 3191 & SVF & $1,54 \mathrm{~b}$ & $\mathrm{P}$ & 7 & Salmão & $12,16 \mathrm{i}$ & $5,16 \mathrm{f}$ & $2,37 \mathrm{~m}$ & $2,99 \mathrm{~b}$ & 0 \\
\hline CMM 3194 & SVF & $1,44 \mathrm{c}$ & A & 1 & Branca & $16,81 \mathrm{~b}$ & 4,301 & $3,96 \mathrm{c}$ & $3,09 \mathrm{~b}$ & 0 \\
\hline CMM 3196 & SVF & $1,73 \mathrm{a}$ & $\mathrm{P}$ & 0 & Salmão & $13,57 \mathrm{~g}$ & $5,06 \mathrm{f}$ & $2,69 \mathrm{j}$ & $3,77 \mathrm{~b}$ & $1,25 \mathrm{~b}$ \\
\hline CMM 3197 & SVF & $1,77 \mathrm{a}$ & A & 0 & Salmão & $13,70 \mathrm{~g}$ & $5,14 \mathrm{f}$ & $2,69 \mathrm{j}$ & $5,12 \mathrm{a}$ & $1,21 \mathrm{~b}$ \\
\hline CMM 3199 & SVF & $1,69 \mathrm{a}$ & $\mathrm{P}$ & 0 & Salmão & $15,13 \mathrm{~d}$ & $4,69 \mathrm{i}$ & $3,24 \mathrm{~g}$ & $3,43 \mathrm{~b}$ & 0 \\
\hline CMM 3200 & SVF & $1,65 \mathrm{~b}$ & $\mathrm{P}$ & 0 & Branca & $15,27 \mathrm{~d}$ & $4,56 \mathrm{j}$ & $3,36 \mathrm{f}$ & $4,14 \mathrm{a}$ & $2,97 \mathrm{a}$ \\
\hline CMM 3202 & MAC & $1,41 \mathrm{c}$ & $\mathrm{P}$ & 4 & Salmão & $14,68 \mathrm{e}$ & $4,04 \mathrm{~m}$ & $3,70 \mathrm{~d}$ & $3,32 \mathrm{~b}$ & $1,03 \mathrm{~b}$ \\
\hline CMM 3204 & MAC & $1,59 \mathrm{~b}$ & $\mathrm{P}$ & 0 & Salmão & $15,13 \mathrm{~d}$ & $4,79 \mathrm{~h}$ & $3,23 \mathrm{~g}$ & 3,96 a & $1,37 \mathrm{~b}$ \\
\hline
\end{tabular}




\begin{tabular}{|c|c|c|c|c|c|c|c|c|c|}
\hline CMM 3208 MAC & $1,82 \mathrm{a}$ & $\mathrm{P}$ & 0 & Salmão & $14,81 \mathrm{e}$ & $4,87 \mathrm{~g}$ & $3,07 \mathrm{~h}$ & $4,36 \mathrm{a}$ & $1,03 \mathrm{~b}$ \\
\hline CMM 3209 MAC & $1,79 \mathrm{a}$ & $\mathrm{P}$ & 0 & Salmão & $14,34 \mathrm{f}$ & $5,04 \mathrm{f}$ & $2,88 \mathrm{i}$ & $4,14 \mathrm{a}$ & $2,06 \mathrm{a}$ \\
\hline CMM 3211 MAC & $1,56 \mathrm{~b}$ & $\mathrm{P}$ & 0 & Salmão & $14,79 \mathrm{e}$ & $4,55 \mathrm{j}$ & $3,31 \mathrm{~g}$ & $3,03 \mathrm{~b}$ & 0 \\
\hline CMM 3213 MAC & $1,80 \mathrm{a}$ & $\mathrm{P}$ & 2 & Salmão & $14,69 \mathrm{e}$ & $5,03 \mathrm{f}$ & $2,95 \mathrm{i}$ & $4,87 \mathrm{a}$ & $0,83 \mathrm{~b}$ \\
\hline CMM 3215 MAC & $1,65 \mathrm{~b}$ & $\mathrm{P}$ & 1 & Salmão & $17,55 \mathrm{a}$ & 4,141 & $4,27 \mathrm{~b}$ & $2,81 \mathrm{~b}$ & $0,79 \mathrm{~b}$ \\
\hline CMM 3218 MAC & $1,73 \mathrm{a}$ & A & 0 & Creme & $14,82 \mathrm{e}$ & $5,22 \mathrm{e}$ & $2,86 \mathrm{i}$ & $3,97 \mathrm{a}$ & $1,93 \mathrm{a}$ \\
\hline CMM 3219 MAC & $1,76 \mathrm{a}$ & $\mathrm{P}$ & 2 & Creme & $16,12 \mathrm{c}$ & $4,92 \mathrm{~g}$ & $3,31 \mathrm{~g}$ & $3,27 \mathrm{~b}$ & $1,04 \mathrm{~b}$ \\
\hline CMM 3220 MAC & $1,77 \mathrm{a}$ & $\mathrm{P}$ & 4 & Branca & $13,40 \mathrm{~g}$ & $5,00 \mathrm{f}$ & $2,71 \mathrm{j}$ & $4,46 \mathrm{a}$ & $1,89 \mathrm{a}$ \\
\hline CMM 3223 MAC & $1,54 \mathrm{~b}$ & $\mathrm{P}$ & 4 & Creme & $16,67 \mathrm{~b}$ & $5,06 \mathrm{f}$ & $3,35 \mathrm{f}$ & $3,46 \mathrm{~b}$ & $0,66 \mathrm{~b}$ \\
\hline CMM 3224 MAC & $1,64 \mathrm{~b}$ & $\mathrm{P}$ & 0 & Salmão & $16,76 \mathrm{~b}$ & 4,271 & $3,97 \mathrm{c}$ & $3,58 \mathrm{~b}$ & $1,00 \mathrm{~b}$ \\
\hline CMM 3225 MAC & $1,65 \mathrm{~b}$ & $\mathrm{P}$ & 5 & Salmão & $16,15 \mathrm{c}$ & $5,38 \mathrm{e}$ & $3,08 \mathrm{~h}$ & $5,06 \mathrm{a}$ & $2,30 \mathrm{a}$ \\
\hline CMM 3226 MAC & $1,81 \mathrm{a}$ & $\mathrm{P}$ & 1 & Salmão & $15,15 \mathrm{~d}$ & $5,24 \mathrm{e}$ & $2,95 \mathrm{i}$ & $4,20 \mathrm{a}$ & $1,77 \mathrm{a}$ \\
\hline CMM 3228 MAC & $1,78 \mathrm{a}$ & $\mathrm{P}$ & 3 & Salmão & $15,72 \mathrm{c}$ & $4,93 \mathrm{~g}$ & $3,24 \mathrm{~g}$ & $2,69 \mathrm{~b}$ & 0 \\
\hline CMM 3231 MAC & $1,91 \mathrm{a}$ & $\mathrm{P}$ & 0 & Salmão & $15,90 \mathrm{c}$ & $4,66 \mathrm{i}$ & $3,44 \mathrm{f}$ & $4,22 \mathrm{a}$ & 0 \\
\hline CMM 3232 MAC & $1,79 \mathrm{a}$ & $\mathrm{P}$ & 1 & Salmão & $13,56 \mathrm{~g}$ & $4,69 \mathrm{i}$ & $2,91 \mathrm{i}$ & $3,70 \mathrm{~b}$ & 0 \\
\hline CMM 3234 MAC & $1,78 \mathrm{a}$ & $\mathrm{P}$ & 4 & Branca & $14,21 \mathrm{f}$ & $6,05 \mathrm{a}$ & $2,39 \mathrm{~m}$ & $3,13 \mathrm{~b}$ & $0,78 \mathrm{~b}$ \\
\hline CMM 3235 MAC & $1,36 \mathrm{c}$ & $\mathrm{P}$ & 6 & Branca & $13,15 \mathrm{~g}$ & $4,56 \mathrm{j}$ & $2,91 \mathrm{i}$ & $3,58 \mathrm{~b}$ & 0 \\
\hline CMM 3238 MAC & $1,77 \mathrm{a}$ & A & 0 & Creme & $12,93 \mathrm{~h}$ & $4,68 \mathrm{i}$ & $2,78 \mathrm{j}$ & $4,65 \mathrm{a}$ & $1,74 \mathrm{a}$ \\
\hline
\end{tabular}

${ }^{1}$ LC: Local de coleta - VIC: Vicência (PE); SVF: São Vicente Férrer (PE); MAC: Machados (PE).

${ }^{2}$ TCMD: Taxa de crescimento micelial diária dos isolados estimada com os dados de leitura de cinco dias em meio BDA, cultivados a $25 \pm 1{ }^{\circ} \mathrm{C}$ e fotoperíodo de $12 \mathrm{~h}$.

${ }^{3} \mathrm{ME}$ : Microescleródios. $\mathrm{A}=$ Ausente; $\mathrm{P}=$ Presente.

${ }^{4}$ Quantidade total de setores presentes nas quatro repetições do isolado.

${ }^{5}$ Descrição baseada na carta de cores de Saccardo (1894) e observada nas quatro repetições, aos seis dias após a repicagem. Os isolados foram cultivados em meio BDA, a $25 \pm 1{ }^{\circ} \mathrm{C}$ e fotoperíodo de $12 \mathrm{~h}$.

${ }^{6,7}$ Média de 100 conídios produzidos em meio BDA, aos sete dias de cultivo a $25 \pm 1{ }^{\circ} \mathrm{C}$ e $12 \mathrm{~h}$ de fotoperíodo.

${ }^{8}$ Média de 100 valores da relação $\mathrm{C} / \mathrm{L}$, calculada pela divisão do comprimento pela largura de cada isolado.

9,10,11 AACPD: Área abaixo da curva de progresso da doença. CF: Com ferimento; SF: Sem ferimento.

*Médias seguidas pela mesma letra na coluna não diferem entre si, pelo teste de agrupamento de $\operatorname{Scott-Knott~}(P=0,05)$.

TABELA 2 - Estimativa da identidade da distância genética de isolados entre três populações de C. musae oriundas de municípios de Vicência (Mata Norte Pernambucana), São Vicenter Férrer e Machados (Agreste Pernambucano).

\begin{tabular}{lccc}
\hline \multicolumn{1}{c}{ População } & Vicência & São Vicente Férrer & Machados \\
\hline Vicência & - & 0,5664 & 0,6944 \\
São Vicente Férrer & 0,5684 & - & 0,7178 \\
Machados & 0,3648 & 0,3315 & - \\
\hline
\end{tabular}

Identidade genética de Nei (1978) (acima da diagonal) e distância genética (abaixo da diagonal).

O valor máximo de 1,0 ocorre quando os mesmos alelos estão nas mesmas frequências, nas populações. 
TABELA 3 - Índices de diversidade genética para isolados de C. musae agrupados em três populações regionais: Vicência (Mata Norte Pernambucana), São Vicenter Ferrer e Machados (Agreste Pernambucano).

\begin{tabular}{ccccccc}
\hline Sub- população & $\begin{array}{c}\text { Tamanho da } \\
\text { Amostra }(n)^{\mathrm{a}}\end{array}$ & $\begin{array}{c}\text { Diversidade } \\
\text { gênica } \\
(H)^{\mathrm{b}}\end{array}$ & $\begin{array}{c}\text { Genótipos } \\
\text { Observados } \\
\left(G_{\mathrm{obs}}\right)^{\mathrm{c}}\end{array}$ & $\begin{array}{c}\text { Riqueza } \\
\text { genotípica } \\
\mathrm{E}\left(g_{n}\right)^{\mathrm{d}}\end{array}$ & $\begin{array}{c}\text { Diversidade } \\
\text { genotípica } \\
(\mathrm{G})^{\mathrm{d}}\end{array}$ & $\begin{array}{c}\text { Equitabilidade } \\
\text { genotípica }^{\left(\mathrm{E}_{5}\right)^{\mathrm{f}}}\end{array}$ \\
\hline Vicência & 20 & 0,20 & 9 & 9 & $4(1,92-6,07)^{\mathrm{g}}$ & 0,855 \\
Machados & 20 & 0,00 & 1 & 1 & $1(1-1)^{\mathrm{g}}$ & 1 \\
São Vicente Ferrer & 20 & 0,129 & 11 & 11 & $7,68(5,13-10,2)^{\mathrm{g}}$ & 0,933 \\
TOTAL & 60 & 0,312 & 21 & 21 & $7,869(5,3-10,4)^{\mathrm{g}}$ & 0,576 \\
\hline
\end{tabular}

ấmero de isolados.

bÍndice de diversidade genotípica de Stoddart e Taylor (1988).

bDiversidade genética de Nei (1973).

¿Número esperado de genótipos estimado pelo método de rarefação, ou seja, o número de genótipos esperados ou a estimativa da riqueza para amostras de menor tamanho (GRÜNWALD et al., 2003), e Índice de diversidade genotípica de Stoddart e Taylor (1988). f'́ndice de equitabiliddade (ALATALO, 1981; LUDWIG; REYNOLDS, 1988; GRÜNWALD et al., 2003).

gOs números em parênteses indicam intervalo de confiança de 95\%, calculado pelo método de bootstrapping (1.000 reamostragem), utilizando o procedimento de bootstrap acelerado (DIXON, 1993; GRÜNWALD et al., 2003).

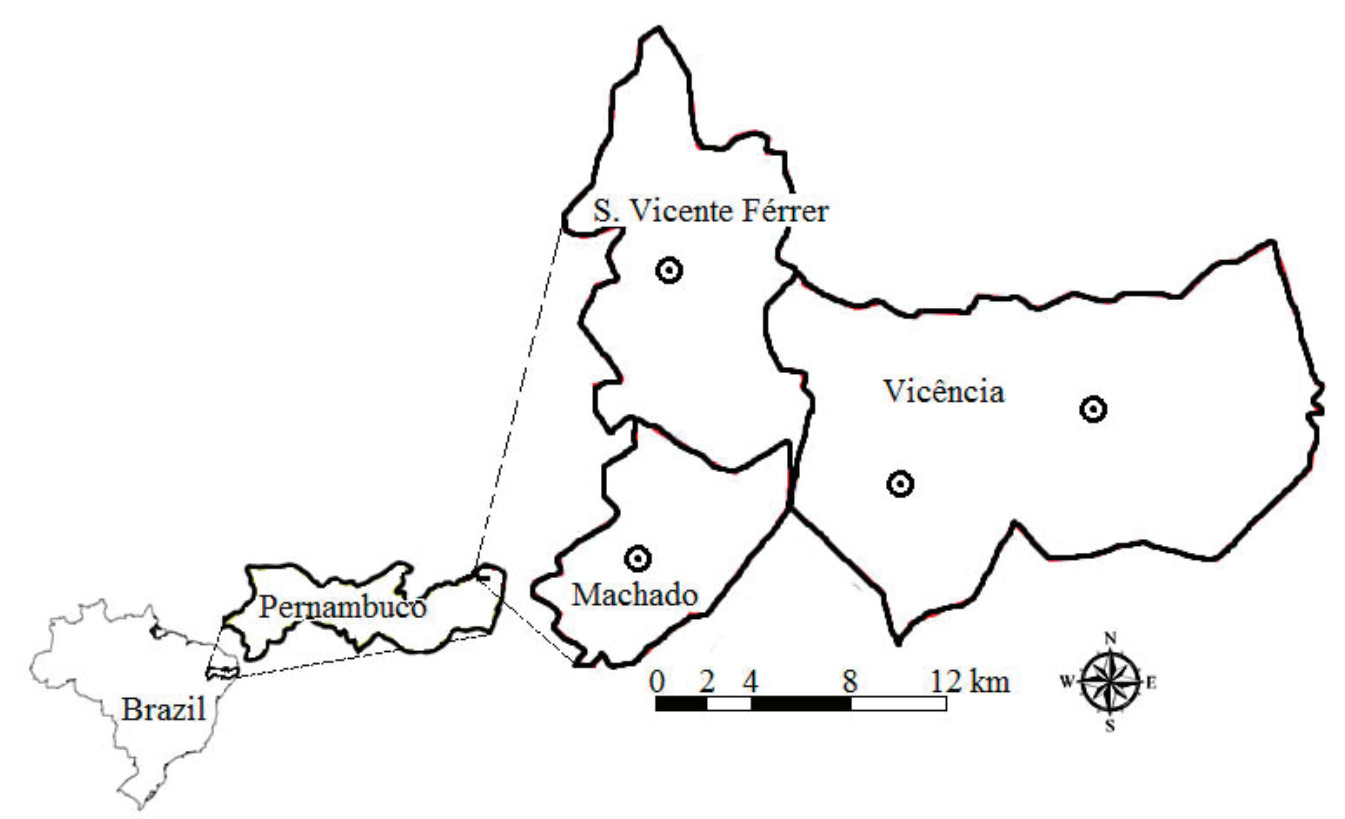

FIGURA 1 - Áreas produtoras de banana amostradas em Pernambuco. 


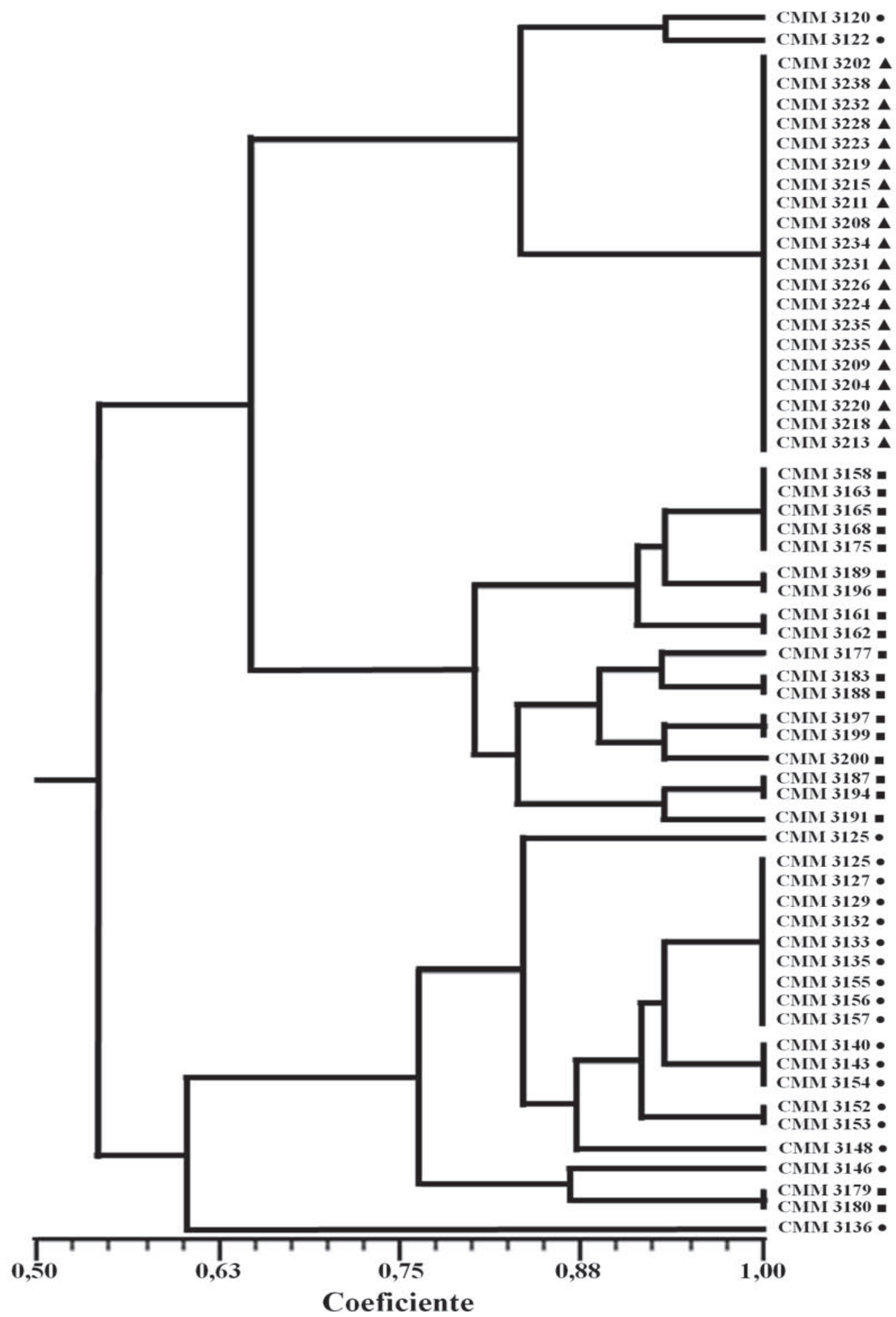

FIGURA 2 - Dendrograma da análise de UPGMA de isolados de C. musae no Estado de Pernambuco: $\Delta$ Machados; - São Vicente Férrer e • Vicência. 


\section{CONCLUSÃO}

Em todas as características fenotípicas avaliadas para os isolados de diferentes áreas produtoras de banana do Estado de Pernambuco, foram observados padrões de variação para $C$. musae, embora todos estivessem dentro dos limites estabelecidos para a espécie.

Há variabilidade genética dos isolados de C. musae dentro de cada área amostrada, exceto na população de Machados.

Os isolados foram patogênicos em frutos de bananeira e diferiram significativamente quanto à virulência em resposta ao método de inoculação.

\section{AGRADECIMENTOS}

Os autores agradecem à Universidade Federal Rural de Pernambuco, pelo apoio institucional, e ao Conselho Nacional de Desenvolvimento Científico e Tecnológico (CNPq), pela concessão de bolsa de mestrado a Paulo Cézar das Mercês Santos (processo n. ${ }^{\text {o: }}$ 133094/2009-0). Os professores Marcos Paz Saraiva Câmara e Sami Jorge Michereff agradecem ao CNPq, pela concessão das bolsas de produtividade.

\section{REFERÊNCIAS}

ABD-ELSALAM, K. A.; ROSHDY, S.; AMIN, O. E.; RABANI, M. First morphogenetic identification of the fungal pathogen Colletotrichum musae (Phyllachoraceae) from imported bananas in Saudi Arabia. Genetics and Molecular Research, Ribeirão Preto, v. 9, p. 2335-2342, 2010.

ALATALO, R. V. Problems in the measurement of evenness in Ecology. Oikos, Copenhagen, v. 37, p. 199-204, 1981.

BAILEY, J.A.; JEGER M.J. Colletotrichum: biology, pathology and control. Wallingford: CAB International, 1992. p.88-120.

CAMPBELL, C. L.; MADDEN, L. V. Temporal analysis of epidemics. I: Description and comparison of disease progress curves. In: CAMPBELL, C. L.; MADDEN, L. V. Introduction to plant disease epidemiology. New York: John Wiley \& SonsInterscience, 1990. p.161-202.

CASELA, C. R.; FREDERIKSEN, R. A. Survival of Colletotrichum graminicola sclerotia in sorghum stalk residues. Plant Disease, Saint Paul, v. 77, p. 825-827, 1993.

CORDEIRO, Z. J. M.; MATOS, A. P. Doenças da banana. Informe Agropecuário, Belo Horizonte, v. 26, p. 12-16, 2005.

CORDEIRO, Z. J. M.; MATOS, A. P.; KIMATI, H. Doenças da bananeira. In: KIMATI, H.; AMORIM, L.; REZENDE, J. A. M.; BERGAMIN FILHO, A.; CAMARGO, L. E. A. (Ed.). Manual de fitopatologia: doenças das plantas cultivadas. 4. ed. São Paulo: Agronômica Ceres, 2005.v.2, p.99-117.

COSTA, R. V.; CASELA, C. R.; ZAMBOLIM, L.; FERREIRA, A. S. A antracnose do sorgo. Fitopatologia Brasileira, Brasília, v. 28, p. 345 354, 2003.

COUTO, E. F.; MENEZES, M. Caracterização fisiomorfológica de isolados de Colletotrichum musae. Fitopatologia Brasileira, Brasília, v. 29, p. 406-412, 2004.

COUTO, E. F.; MENEZES, M.; COÊLHO, R. S. B. Avaliação da patogenicidade e diferenciação enzimática em meio sólido específico de isolados de Colletotrichum musae. Summa Phytopathologica, Botucatu, v. 28, p. 260-266, 2002.

DIXON, P. M. The bootstrap and the jackknife: describing the precision of ecological indices. In: SCHEINER, S. M.; GUREVITCH, J. (Ed.). Design and analysis of ecological experiments. New York: Chapman \& Hall, 1993. p. 290-318.

FREEMAN, S.; SHABI, E. Cross-infection of subtropical and temperate fruits by Colletotrichum species from various hosts. Physiology Molecular Plant Pathology, Maryland, v. 49, p. 395-404, 1996.

FREEMAN, S.; REDMAN, R. S.; GRANTHAM, G.; RODRIGUEZ, R. J. Characterization of a linear DNA plasmid from the filamentous fungal plant pathogen Glomerella musae [Anamorph: Colletotrichum musae (Berk. \& Curt.) Arx.]. Current Genetics, Heidelberg, v. 32, p.152-156, 1997.

GRÜNWALD, N. J.; GOODWIN S. B.; MILGROOM, M.G.; FRY, W. E. Analysis of genotypic diversity data for populations of microorganisms. Phytopathology, Saint Paul, v. 93, p.738-746, 2003.

HILL, M. O. Diversity and evenness: a unifying notation and its consequences. Ecology, Washington, v. 54, n. 2, p. 427-432, 1973.

HO, W.-C.; KO, W.-H. A simple method for obtaining single-spore isolates of fungi. Botanical Bulletin of Academia Sinica, Taipei, v. 38, p. 41-44, 1997. 
JUNGHANS, D. T.; GOMES, E. A.; GUIMARÃES, W. V.; BARROS, E. G.; ARAUJO, E. F. Genetic diversity of the ectomycorrhizal fungus Pisolithus tinctorius based on RAPD-PCR analysis. Mycorrhiza, Oregon, v. 7, p. 243-248, 1998.

LUDWIG, J. A.; REYNOLDS, J. F. Diversity indices. In: LUDWIG, J. A.; REYNOLDS, J. F. Statistical ecology: a primer on methods and computing. New York: John Wiley \& Sons, 1988. p. 85-103.

McDONALD, B. A; LINDE, C. The population genetics of plant pathogens and breeding strategies for durable resistance. Euphytica, Dordrecht, v. 124, p.163-180, 2002.

MEDEIROS L. V.; MACIELD. B.; MEDEIROS V.V.; HOULLOU KIDO L. M.; OLIVEIRAN. T. pelB gene in isolates of Colletotrichum gloeosporioides from several hosts. Genetic Molecular Resarch, Ribeirão Preto, v. 9, p. 661-673, 2010.

NEI, M. Analysis of gene diversity in subdivided populations. Proceedings of the National Academy of Sciences of the United States of America, Washington, v. 70, p. 3321-3323, 1973.

NEI, M. Estimation of average heterozygosity and genetic distance from a small number of individuals. Genetics, Madison, v. 89, n. 3, p. 583-590, 1978.

PHOTITA, W.; TAYLOR, P. W. J.; FORD, R.; HYDE, K. D.; LUMYONG, P. Morphological and molecular characterization of Colletotrichum species from herbaceous plants in Thailand. Fungal Diversity, Kunming, v. 18, p. 117-133, 2005.

ROCA-MAGALLANES, M. G.; MACHADO, J. C.; VIEIRA, M. G. G. C.; DAVIDE, L. C.; ROCHA, M. L. M. Compatibilidade sexual e vegetativa do complexo Glomerella-Colletotrichum associado a sementes de algodão. Fitopatologia Brasileira, Brasília, v. 29, p. 16-20, 2004.

SACCARDO, P. A. Chromotaxia seu nomenclator colorum polyglottus additis speciminibus coloratis ad usum botanicorum et zoologorum. Patavii: Typis Seminarii, 1894. 22 p.

SCHÄFER, C.; WÖSTEMEYER, J. Random primer dependent PCR differentiates aggressive from nonaggressive isolates of the oilseed rape pathogen Phoma lingam (Leptosphaeria maculans). Journal of Phytopathology, Berlin, v. 136, p.124-136, 1992.
SHANER, G.; FINNEY, R. E. The effect of nitrogen fertilization on the expression of slow-mildewing resistance in Knox wheat. Phytopathology, Saint Paul, v. 67, p. 1051-1056, 1977.

STODDART, J. A.; TAYLOR, J. F. Genotypic diversity: estimation and prediction in samples. Genetics, Madison, v. 118, p. 705-711, 1988.

SU, Y.Y.; NOIREUNG, P.; LIU, F.; HYDE, K. D.; MOSLEM, M. A.; BANKALI, A. H.; ABDELSALAM, K. A.; CAI, L. Epitypification of Colletotrichum musae, the causative agent of banana anthracnose. Mycoscience, Tokyo, v. 52, p. 376-382, 2011.

SUTTON, B. C. The genus Glomerella and its anamorph Colletotrichum. In: BAILEY, J. A.; JEGER, M. J. (Ed.). Colletotrichum: biology, pathology and control. Wallingford: Centre for Agriculture and Biosciences International, 1992. p. $1-26$.

THAN, P. P.; JEEWON, R.; HYDE, K. D.; PONGSUPASAMIT, S.; MONGKOLPORN, O.; TAYLOR, P. W. J. Characterization and pathogenicity of Colletotrichum species associated with anthracnose on chilli (Capsicum spp.) in Thailand. Plant Pathology, Oxford, v. 57, p. 562$572,2008$.

TOZZE JÚNIOR, H. J. Caracterização e identificação de espécies de Colletotrichum associadas à antracnose do pimentão (Capsicum annuum) no Brasil. 2007. 81 f. Dissertação (Mestrado em Fitopatologia) - Escola Superior de Agricultura “Luiz de Queiroz", Universidade de São Paulo, Piracicaba, 2007.

UDAYANGA, D.; MANAMGODA, D. S.; LIU, X.; CHUKEATIROTE, E.; HYDE, K. D. What are the common anthracnose pathogens of tropical fruits? Fungal Diversity, Kunming v. 61, p.165-179, 2013.

VENTURA, J. A.; HINZ, R. H. Controle das doenças da bananeira. In: ZAMBOLIN, L.; VALE, F. X. R.; MONTEIRO, A. J. A.; COSTA, H. (Ed.). Controle de doenças de plantas: fruteiras. Viçosa: Suprema Gráfica e Editora Ltda., v. 2, 2002. p. 839-938.

ZAKARIA, L.; SAHAK, S.; ZAKARIA, M.; SALLEH, B. Characterization of Colletotrichum species associated with anthracnose of banana. Tropical Life Sciences Research, Kedah, v. 20, p. 119-125, 2009. 